\title{
Classification of COVID-19 in intensive care patients
}

\author{
Xiaofan Lu ${ }^{1 \dagger}$, Yang Wang ${ }^{2 \dagger}$, Taige Chen ${ }^{3 \dagger}$, Jun Wang ${ }^{4 \dagger}$ and Fangrong Yan ${ }^{1 *}(\mathbb{D}$
}

Dear Editor,

Previous studies on coronavirus disease 2019 (COVID19) mainly described patients' general information [1]. We aimed to bridge the gap between disease classification and clinical outcome in intensive care patients, which could help in the individual evaluation and provide effective triage for treatment and management.

One hundred fifty-one intensive care patients with complete medical records were obtained from Tongji Hospital in Wuhan, China. Data on the day of admission were collected, including six data categories: demographic information of age and gender, symptoms ([>10\%] fever, fatigue, dry cough, anorexia, myalgia, dyspnea, expectoration, diarrhea), original comorbidities ([>5\%] hypertension, diabetes, cardiovascular disease [CVD], chronic obstructive pulmonary disease [COPD], malignancy), vital signs (respiratory rate, heart rate, blood pressure, $\mathrm{SpO}_{2}$, $\mathrm{FiO}_{2}$ ), blood routine tests (count of WBC, lymphocyte, neutrophil, platelet and monocyte, red cell distribution width [RDW]), and inflammatory marker measurements (high-sensitivity C-reactive protein [hs-CRP], interleukin-2 receptor [IL-2R], IL-6, IL-8, IL-10, TNF- $\alpha$ ). Blood routine tests were also measured at days 3 and 5 since admission, and adjuvant corticosteroid therapy throughout the disease course was retrieved. Clinical outcome was 28-day mortality after admission. The Ethics Commission of Tongji Hospital approved this study, with a waiver of informed consent. We constructed a fully Bayesian latent variable model for integrative clustering of the

\footnotetext{
* Correspondence: f.r.yan@163.com

${ }^{+}$Xiaofan Lu, Yang Wang, Taige Chen and Jun Wang contributed equally to this work.

${ }^{1}$ State Key Laboratory of Natural Medicines, Research Center of Biostatistics and Computational Pharmacy, China Pharmaceutical University, Nanjing 210009, China

Full list of author information is available at the end of the article
}

six data categories [2]. The appropriate clustering number was determined by minimizing the Bayesian information criterion. Only features with high posterior probability (e.g., 0.8) were kept.

We identified four prognostic types of COVID-19 (Fig. 1). The characteristics of the four types were described below (Table 1). Type A: Extremely poor prognosis and elderly enriched; Dry cough, dyspnea, and fatigue were common symptoms; hypertension, diabetes, and CVD were common preexisting medical conditions. $\mathrm{Pa}-$ tients presented severe respiratory failure, dramatically elevated counts of WBC and neutrophil, and lymphocyte depletion. Remarkably elevated cytokine occurred, accompanied by later development of ARDS and multiple organ failure. Type B: Poor prognosis and elderly enriched; dyspnea and cough with expectoration were common symptoms, accompanied by diarrhea and anorexia. Unfavorable respiratory condition and decreased lymphocyte count could be observed. Patients presented an imminent elevation of cytokine and a high risk of developing ARDS and multiple organ failure later after treatment. Type C: Intermediate prognosis; symptoms of dry cough and fatigue, and original comorbidity of hypertension were common. The respiratory condition was normal, and most laboratory tests were within normal or moderately elevated. Type D: Favorable prognosis and middle age enriched; primary symptom was cough with expectoration. Patients had stable breathing and most laboratory tests were in a normal range or slightly elevated.

This report, to our knowledge, is the first attempt of dealing with the classification of COVID-19 in intensive care patients. The four prognostic types present a stepwise distribution in age, respiratory condition, and inflammatory markers, suggesting their prognostic efficacy. The specificity of symptoms does not appear to be strong, but gastrointestinal response (e.g., diarrhea) 

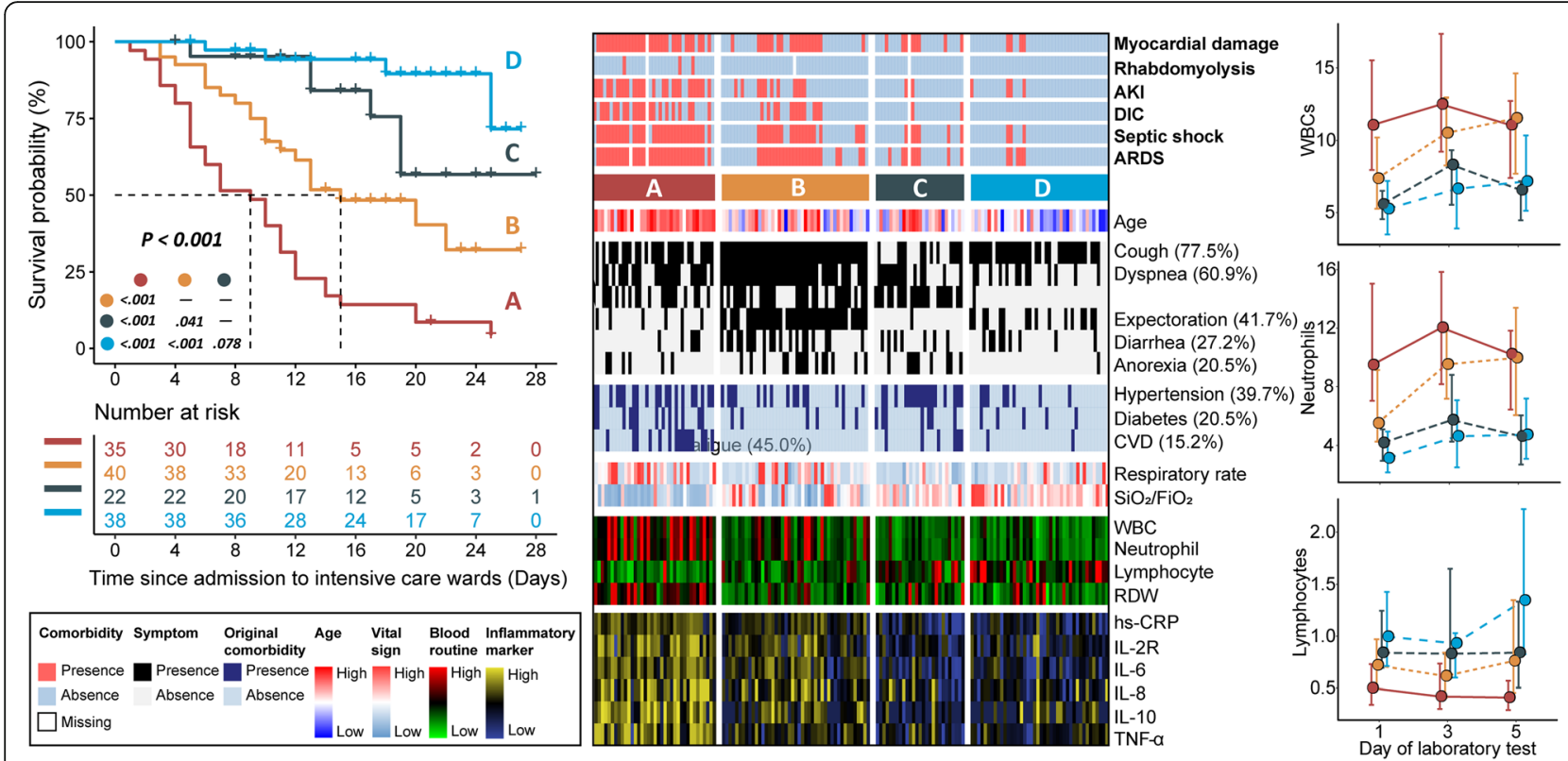

Fig. 1 Clinical landscape of four prognostic types of COVID-19 in intensive care patients. Kaplan-Meier survival curves (left panel) showing differential survival rates; comprehensive heatmap (middle panel) delineating clinical landscape of different types of COVID-19, with legend positioning in the left bottom panel; time line charts (right panel) profiling the dynamic measurement (median [IQR], $\times 10^{9} / \mathrm{L}$ ) of blood routine tests at days 1, 3, and 5 since admission among four prognostic types. Survival was analyzed with log-rank test and pair-wise comparison was adjusted by Benjamini-Hochberg method. Labels of "high" and "low" were based on data interval instead of clinical reference values. AKl: acute kidney injury; DIC: disseminated intravascular coagulation; ARDS: acute respiratory distress syndrome; CVD: cardiovascular disease; $\mathrm{SpO}_{2}$ : peripheral oxygen saturation; $\mathrm{FiO}_{2}$ : fraction of inspired oxygen; WBC: white blood cell; RDW: red cell distribution width 
Table 1 Presenting characteristics of four types of COVID-19 in intensive care patients $(n=151)$

\begin{tabular}{|c|c|c|c|c|}
\hline & A $(\boldsymbol{n}=37)$ & B $(\boldsymbol{n}=45)$ & $C(\boldsymbol{n}=27)$ & $\mathrm{D}(\boldsymbol{n}=42)$ \\
\hline Age, years & $77(70-81)$ & $62(52-70)$ & $65(51-74)$ & $53(43-58)$ \\
\hline \multicolumn{5}{|l|}{ Signs and symptoms } \\
\hline Cough & $26(70)$ & $45(100)$ & $12(44)$ & $34(81)$ \\
\hline Dyspnea & $24(65)$ & $41(91)$ & $14(52)$ & $13(31)$ \\
\hline Fatigue & $19(51)$ & $27(60)$ & $21(78)$ & 1 (2) \\
\hline Expectoration & $6(16)$ & $40(89)$ & $1(4)$ & $16(38)$ \\
\hline Diarrhea & $5(14)$ & $20(44)$ & $7(26)$ & $9(21)$ \\
\hline Anorexia & $6(16)$ & $15(33)$ & $9(33)$ & $1(2)$ \\
\hline \multicolumn{5}{|l|}{ Original comorbidities } \\
\hline Hypertension & $20(54)$ & $15(33)$ & $17(63)$ & $8(19)$ \\
\hline Diabetes & $13(35)$ & $6(13)$ & $7(26)$ & $5(12)$ \\
\hline CVD & $15(41)$ & 0 & $6(22)$ & $2(5)$ \\
\hline \multicolumn{5}{|l|}{ Vital signs } \\
\hline Respiratory rate, rpm & $25(20-32)$ & $22(20-26)$ & $20(20-23)$ & $21(20-25)$ \\
\hline $\mathrm{SpO}_{2} / \mathrm{FiO}_{2}$ & $99(90-158)$ & $222(100-294)$ & $297(237-336)$ & $298(248-345)$ \\
\hline
\end{tabular}

Laboratory findings

Routine blood test

\section{WBCs, $\times 10^{9} / \mathrm{L}$}

Day 1

Day 3

Day 5

Absolute lymphocytes, $\times 10^{9} / \mathrm{L}$

$\begin{array}{lc}\text { Day } 1 & 0.5(0.3-0.7) \\ \text { Day } 3 & 0.4(0.3-0.7) \\ \text { Day } 5 & 0.4(0.3-0.6)\end{array}$

Absolute neutrophils, $\times 10^{9} / \mathrm{L}$

Day 1
Day 3
Day 5
RDW-CV
Inflammatory marker
hs-CRP, mg/L
IL-2R, U/ml
IL-6, pg/ml
IL-8, pg/ml
IL- $10, \mathrm{pg} / \mathrm{ml}$
$\mathrm{TNF}-\mathrm{a}, \mathrm{pg} / \mathrm{ml}$

Corticosteroid therapy

$11.1(8.0-15.5)$

$12.5(9.2-17.4)$

$11.1(7.4-12.7)$

$0.4(0.3-0.6)$

\section{$9.5(7.1-15.0)$}

$12.0(8.2-15.8)$

$10.2(6.5-11.8)$

$13.4(12.8-14.1)$

$126(76-190)$

1341 (940-1809)

68 (37-137)

$42(21-95)$

$15(9-24)$

$15(10-23)$

28 (76)
$7.4(5.3-10.2)$

$10.5(8.3-12.9)$

$11.5(7.7-14.6)$

$0.7(0.5-1.0)$

$0.6(0.4-0.8)$

$0.8(0.5-1.3)$

$5.5(4.3-9.1)$

$9.5(7.2-12.0)$

$10.0(6.1-13.4)$

$12.2(11.9-12.8)$

80 (42-109)

1038 (678-1185)

43 (21-79)

21 (13-40)

7 (3-11)

$9(8-11)$
$5.6(4.5-6.5)$

$8.3(5.5-9.3)$

$6.6(4.5-7.2)$

$0.8(0.7-1.2)$

$0.8(0.6-1.7)$

$0.8(0.5-1.3)$

$4.2(3.0-5.1)$

$5.7(4.3-8.8)$

$4.6(2.7-6.1)$

$12.6(11.8-13.0)$

$19(5-49)$

701 (430-813)

$10(2-20)$

$12(7-24)$

$3(3-6)$

7 (5-9)

13 (48)
$5.2(3.5-7.2)$

6.6 (3.9-8.3)

$7.2(5.1-10.3)$

$1.0(0.7-1.4)$

$0.9(0.6-1.0)$

$1.3(0.8-2.2)$

$3.1(2.2-5.0)$

$4.6(2.5-7.1)$

$4.7(3.1-7.2)$

$12.2(11.8-12.7)$

$28(10-70)$

685 (439-928)

$14(5-30)$

15 (10-21)

3 (3-9)

$8(7-10)$

27 (64)

Continuous variables were described as median (IQR) while categorical variables were expressed as frequencies (\%). All records were measured at admission to intensive care wards unless otherwise indicated. Multiple group comparison was done with Kruskal-Wallis test; proportions for categorical variables were compared using Fisher's exact test. All calculated $P$ values were less than or equal to 0.001 except for respiratory rate $(P=0.004)$, absolute lymphocytes at day 3 since admission $(P=0.013)$, and corticosteroid therapy $(P=0.013)$

Abbreviations: CVD cardiovascular disease, rpm breaths per minute, $\mathrm{SpO}_{2}$ peripheral oxygen saturation, $\mathrm{FiO}_{2}$ fraction of inspired oxygen, WBC white blood cell, $R D W$ red cell distribution width

needs vigilance [3]. Unexpectedly, hypertension is more evenly distributed, which contradicts previous study indicating hypertensive with COVID-19 was more likely to be in a high risk of mortality [4]. Notably, types A and B always showed higher content of WBCs and neutrophils, no matter on days 1, 3 , or 5 since admission, while types $C$ and $D$ had relatively higher lymphocyte counts compared to other types; such trend seemed not to be affected by corticosteroids even though more patients in types A and $\mathrm{B}$ received adjuvant corticosteroids therapy than $\mathrm{C}$ and D. Investigations in larger cohorts are required to provide more evidence. The study is limited by ignoring the potential treatment effect. However, such classification could help in better triage, allowing for a more rational allocation of scarce medical resources in a resource-constrained environment. 


\section{Acknowledgements}

We would like to thank all the hospital staff members for their efforts in collecting the information that was used in this study, and all the patients who consented to donate their data for analysis and the medical staff members who are on the front line of caring for patients.

\section{Authors' contributions}

Conceptualization: X. Lu. Acquisition, analysis, or interpretation of data: J. Wang, Y. Wang, X. Lu, and T. Chen. Statistical analysis: X. Lu and F. Yan. Investigation: $X . L u, T$. Chen, and Y. Wang. Drafting of the manuscript editing: $X$. Lu, T. Chen, and Y. Wang. Funding acquisition: J. Wang, Y. Wang, and F. Yan. Supervision: J. Wang and F. Yan. The authors read and approved the final manuscript.

\section{Funding}

This work was supported by the National Key R\&D Program of China (2019YFC1711000), the National Natural Science Foundation of China (81973145), the "Double First-Class" University Project (CPU2018GY09), the China Postdoctoral Science Foundation (2019 M651805), the Science Foundation of Jiangsu Commission of Health (H2018117), and the Emergency Project for the Prevention and Control of the Novel Coronavirus Outbreak in Suzhou (SYS2020012).

\section{Availability of data and materials}

Drs. J. Wang had full access to all of the data in the study. After publication, the data will be made available to others on reasonable requests after approval from the author (J.W, dr_wangjun@suda.edu.cn) and Wuhan Tongji Hospital.

\section{Ethics approval and consent to participate}

Ethical approval was waived by the Ethics Committee of Tongji Hospital (Wuhan, China) in view of the retrospective and observational nature of the study, and all the procedures being performed were part of the routine care.

\section{Consent for publication}

The informed consents of patients were waived by the Ethics Commission of Tongji Hospital (Wuhan, China) for the rapid emergence of this epidemic.

\section{Competing interests}

The authors declare that they have no competing interests.

\section{Author details}

${ }^{1}$ State Key Laboratory of Natural Medicines, Research Center of Biostatistics and Computational Pharmacy, China Pharmaceutical University, Nanjing 210009, China. ${ }^{2}$ Department of Radiology, The Affiliated Nanjing Drum Tower Hospital of Nanjing University Medical School, Nanjing 210008, China. ${ }^{3}$ Medical School of Nanjing University, Nanjing 210093, China. ${ }^{4}$ Department of Intensive Care Medicine, The First Affiliated Hospital of Soochow University, Suzhou 215006, China.

Received: 13 May 2020 Accepted: 1 July 2020

Published online: 09 July 2020

\section{References}

1. Guan W-j, Ni Z-y, Hu Y, Liang W-H, Ou C-Q, He J-X, Liu L, Shan H, Lei C-L, Hui DSC et al: Clinical characteristics of coronavirus disease 2019 in China. N Engl J Med. 2020;382(18):1708-20

2. Mo Q, Shen R, Guo C, Vannucci M, Chan KS, Hilsenbeck SG. A fully Bayesian latent variable model for integrative clustering analysis of multi-type omics data. Biostatistics. 2018;19(1):71-86.

3. Liang W, Feng Z, Rao S, Xiao C, Xue X, Lin Z, Zhang Q, Qi W. Diarrhoea may be underestimated: a missing link in 2019 novel coronavirus. Gut. 2020; 69(6):1141-3.

4. Zhou F, Yu T, Du R, Fan G, Liu Y, Liu Z, Xiang J, Wang Y, Song B, Gu X. Clinical course and risk factors for mortality of adult inpatients with COVID19 in Wuhan, China: a retrospective cohort study. Lancet. 2020;395(10229): 1054-62.

\section{Publisher's Note}

Springer Nature remains neutral with regard to jurisdictional claims in published maps and institutional affiliations.

Ready to submit your research? Choose BMC and benefit from:

- fast, convenient online submission

- thorough peer review by experienced researchers in your field

- rapid publication on acceptance

- support for research data, including large and complex data types

- gold Open Access which fosters wider collaboration and increased citations

- maximum visibility for your research: over $100 \mathrm{M}$ website views per year

At $\mathrm{BMC}$, research is always in progress.

Learn more biomedcentral.com/submissions 